\title{
Die Narrationes der Urkunden Kaiser Sigismunds für böhmische Empfänger aus den Jahren 1433-1437 und die Umgestaltung der Erinnerung an die Hussitenkriege
}

\section{The narrationes in charters of Emperor Sigismund for Czech recipients 1433-1437 and transformations in remembering the Hussite Wars}

Petr Elbel / elbel@phil.muni.cz

Ústav pomocných věd historických a archivnictví FF MU

\begin{abstract}
This study focuses on the memorial function of charters in the Late Middle Ages based on narrationes in Sigismund of Luxemburg's charters for Czech recipients from 1433 to 1437. This dramatic period saw the culmination of the Hussite Wars (the siege of Plzeň, the Battle of Lipany), while at the same time there were negotiations between the Hussites and the Council of Basel which resulted in the issuing of the Basle Compacts and the acceptance of Emperor Sigismund as King of Bohemia in July 1436. The author gradually describes narrationes in Sigismund's charters for Bohemian Catholics from 1433 to 1435 and 1436 to 1437, and finally also for the Utraquists from 1436 to 1437. He demonstrates that while from 1433 to 1435 the charters were a means of fixing the Catholic towns' and noble families' memory of their continued and gallant struggle against "Hussite heresy" in writing, from 1436 to 1437 Sigismund's chancery retrospectively modified the memory of the previous wars in an effort to harmonise the image created in these charters with the religious reconciliation of July 1436.
\end{abstract}

\section{Keywords}

charters, narratio, historical memory, Emperor Sigismund of Luxemburg, Hussite Wars, Basel Compacts

Der Beitrag entstand im Rahmen des durch die Czech Science Foundation geförderten Forschungsprojektes GA15-14758S „Emperor Sigismund's Party in Hussite Bohemia”. Der Autor dankt Dr. Alexandra Kaar (Prag) für sprachliche Korrekturen. 
Der vorliegende Beitrag beschäftigt sich mit den vielschichtigen Memorial-Funktionen spätmittelalterlicher Herrscherurkunden. Dabei soll nicht der Anschein erweckt werden, dass es sich bei diesem Faktor um die hauptsächliche Funktion dieser Urkunden im Spätmittelalter handelte. Bekanntermaßen waren Urkunden zu dieser Zeit fix in die Rechtskultur und -praxis eingebettet. Die Ausfertigung von Urkunden und Notariatsinstrumenten sowie deren Übertragung in diverse Amtsbücher waren integrale Bestandteile von Rechtsgeschäften; der Verschriftlichung kam bei diesen Handlungen eine konstitutive Rolle zu.

Die meisten Rechtsgeschäfte waren jedoch darüber hinaus immer noch von ritualisierten öffentlichen Handlungen begleitet und die Urkunden bewahrten neben ihrer rechtsbegründenden Funktion gleichzeitig auch die Erinnerung an die gleichermaßen rechtsbegründende ritualisierte Handlung. Aus diesem Grund wurde die das Rechtsgeschäft begleitende symbolische Kommunikation oft detailliert in den Urkunden und Notariatsinstrumenten beschrieben. Das Verhältnis von Urkunde und Ritual und deren Zusammenwirken scheint bei verschiedenen Rechtsinstituten und in unterschiedlichen sozialen Milieus variiert zu haben und es ist eine der langfristigen Aufgaben der diplomatischen und rechtsgeschichtlichen Forschung, dieses Verhältnis auch für das Spätmittelalter zu untersuchen. ${ }^{1}$

Die Memorial-Funktion spätmittelalterlicher Urkunden war jedoch mit der Bewahrung der Erinnerung an die rituelle Komponente eines Rechtsakts nicht erschöpft. Urkunden konnten nämlich auch der Memoria anderer, vom eigentlichen Rechtsakt unabhängiger Ereignisse dienen, wie etwa eines kaiserlichen Besuchs in einer Stadt oder der Teilnahme des Empfängers an einem Kriegszug. Diesen Tatsachen wurde oft lediglich in den Datierungsformeln gedacht, die aus diesem Grund auch leicht modifiziert werden konnten. ${ }^{2}$

1 Obwohl es sich um ein breites Forschungsfeld handelt, gibt es bisher noch wenige Arbeiten zu diesem Themenkreis. Für Böhmen sind z. B. die anregenden Forschungen zur Investitur von Geistlichen mit Kirchenpfründen zu nennen, für die die gesamte Palette der mit diesem Prozedere verbundenen Schriftstücke und Rituale untersucht wurde. Aus diesen Untersuchungen geht klar hervor, dass der Prozess der Investitur mehrstufig war, wobei die einzelnen Schriftstücke und Rituale eine Gesamtheit bildeten und gemeinsam wirkten. Siehe vor allem Zilynská, Blanka: „Vestre reverendissime paternitati duximus presentandum“. Role a podoba písemností při obsazováni církevnich beneficií ve středověku [„Vestre reverendissime paternitati duximus presentandum “. Rolle und Gestalt von Schriftstücken bei der Besetzung von Kirchenbenefizien im Mittelalter]. In: Pragmatické písemnosti v kontextu právním a správním. Hg. von Zdeněk Hojda - Hana Pátková. Opera Facultatis philosophicae Universitatis Carolinae Pragensis 6. Praha 2008, S. 105-119; Hrdina, Jan: O klobouku, klericích a patronovi. Netradični forma prezentace plebána k farnímu beneficiu pražské diecéze na počátku 15. století [Von einem Hut, Klerikern und Patronen. Eine unübliche Form der Präsentation eines Plebans auf ein Pfarrbenefiz in der Prager Erzdiözese zu Beginn des 15. Jahrhunderts]. In: Církevní topografie a farní sít pražské církevní provincie v pozdním středověku. Hg. von Blanka Zilynská - Jan Hrdina. Colloquia Mediaevalia Pragensia 8. Praha 2007, S. 199-207.

2 Offensichtlich waren insbesondere Städte daran interessiert, königliche Urkunden während eines Aufenthaltes des Herrschers in der Stadt zu erwerben, wobei dann die Datierungsformel der jeweiligen Urkunden an diesen Aufenthalt erinnern konnte. Diese persönliche Gegenwart wurde sogar teilweise fingiert, wenn der König während eines Besuchs entschied, dass eine Urkunde ausgestellt werden sollte, die Urkunde aber erst nach der Abreise ausgefertigt wurde. Das Tagesdatum entsprach dann dem Zeitpunkt der Ausfertigung und die betreffende Stadt wurde als Ausstellungsort genannt, obwohl der Hof bereits weitergezogen war. Ein Beispiel für ein solches Vorgehen stellt eine Urkunde König Sigismunds 
Am engsten unter den Urkundenformeln war aber die Narratio mit dem Memorialaspekt verflochten. Wie die Handbuchdefinitionen erläutern, resümiert die Narratio meist die unmittelbaren Hintergründe der Urkundenausstellung, also hauptsächlich den rechtlichen oder finanziellen Hintergrund eines Rechtsgeschäfts, wie etwa den Verlauf des vorangehenden Prozesses in einem Urteilsbrief oder die Genese und Zusammensetzung der zu begleichenden Forderungen in einem Schuld- oder Pfandbrief.

Etliche Narrationes enthalten darüber hinaus noch zusätzliche Informationen, die für den in der Dispositio festgehaltenen Rechtsakt beinahe bzw. vollkommen irrelevant sind und ganz andere Erinnerungen fixieren. Es handelt sich dabei z. B. um die Hervorhebung der (Ver-)Dienste des Empfängers dem Aussteller gegenüber, die Betonung der freundschaftlichen Beziehungen zwischen dem Empfänger und dem Aussteller, oder aber die Hervorhebung der ritterlichen Tugenden eines adeligen, bzw. des frommen Lebenswandels eines geistlichen Empfängers. ${ }^{3}$ Alle diese Formulierungen sollten eine bestimmte Memoria fixieren oder konstituieren und haben daher eher symbolische, als praktische oder rechtliche Bedeutung.

Im vorliegenden Beitrag wird die eben skizzierte Funktion von Narrationes untersucht, und zwar am Beispiel der Urkunden Kaiser Sigismunds für böhmische Empfänger aus den Jahren 1433-1437. Gleich zu Anfang muss vorausgeschickt werden, dass die potentiell signifikantesten Beispiele für die Memorial-Funktion von Narrationes, die man im umfangreichen Urkundenauslauf Sigismunds finden kann, wahrscheinlich außerhalb dieser Stichprobe liegen. Diese Beispiele sind im Wirkungsgebiet der ungarischen königlichen Kanzleien zu suchen, wo die Urkunden seit dem Hochmittelalter oft sehr lange Narrationes enthielten, die die tapferen Taten des Empfängers und dessen Verdienste für den Aussteller unter Einsatz der etablierten Ausdrucksmittel der ritterlich-höfischen Kultur detailliert darstellten. Der Urkundenbestand eines adeligen Familienarchivs bildete daher oft eine Art Familienchronik, die das Familiengedächtnis eines Geschlechts bewahrte. ${ }^{4}$

für die mährische Stadt Ungarisch Hradisch dar, die am 5. April 1421 angeblich in Ungarisch Hradisch ausgestellt wurde, obwohl Sigismund lediglich vom 14. bis zum 18. März 1421 in der Stadt weilte und von dort aus nach Znaim und Brünn weiterzog, wo er sich vom 1. bis zum 7. April aufhielt. Sigismund befreite Ungarisch Hradisch mit seiner Urkunde auf fünf Jahre von sämtlichen Steuern, wodurch er Schäden ausgleichen wollte, die die Stadt im Zuge des jüngsten Aufenthalts seiner Truppen erlitten hatte - siehe J. F. Böhmer, Regesta Imperii. XI. Regesten Kaiser Sigismunds (1410-1437) nach Archiven und Bibliotheken geordnet. Herausgegeben von Karel Hruza. 1. Die Urkunden und Briefe aus den Archiven und Bibliotheken Mährens und Tschechisch-Schlesiens. Nach Wilhelm Altmann neubearbeitet von Petr Elbel. Wien - Köln - Weimar 2012 (= RI XI NB/1), S. 96-98, Nr. 40; zum Itinerar Engel, Pál - C. Tóth, Norbert: Itineraria regum et reginarum (1382-1438) [...]. Subsidia ad historiam medii aevi Hungariae inquirendam 1. Budapest 2005, S. 107-108. Ähnliche Fälle, in denen schon die Datierung eine bestimmte Memoria vermittelt, stellen jene Urkunden dar, die der König „im Feld bei/vor...“ ausstellte. Die Urkunde wurde dabei zu einem Denkmal der Anwesenheit des Empfängers im königlichen Heer, was dessen in der Urkunde hervorgehobenen Verdienste noch unterstreichen konnte. Ein solches Beispiel stellt die Urkunde Sigismunds für das Haus Liechtenstein dar, die am 3. Oktober 1425 auf Bitten Hartneids V. von Liechtenstein im Feld vor Pohrlitz ausgestellt wurde - siehe RI XI NB/1, S. 181-182, Nr. 129.

3 Verschiedene Belege werden weiter unten besprochen, da der Beitrag gerade diese Aspekte der Memorial-Funktion spätmittelalterlicher Urkunden untersucht.

4 Daniela Dvořáková hat die Narrationes der Schenkungsurkunden Sigismunds für ungarische Adelige in 
In der Reichskanzlei Sigismunds, die auch den Urkundenauslauf für die böhmischen Empfänger besorgte, waren Narrationes bei weitem weniger ausgeprägt und verbreitet, da hier eine andere Tradition vorlag. Die Taten des Urkundenempfängers wurden - zwar unregelmäßig, aber auch nicht selten - vor allem in Wappenbriefen und Standeserhöhungsurkunden dargestellt, wobei hier ungarische Einflüsse nicht auszuschließen sind. Dies gilt jedenfalls für die gefälschten Standeserhöhungsurkunden Kaspar Schlicks, die die Laufbahn des Kanzlers in Sigismunds Diensten sehr detailliert und oft völlig übertrieben darstellen und sich dabei dem ungarischen Usus annähern. ${ }^{5}$

Die weiter unten besprochenen Urkunden Sigismunds für die böhmischen Empfänger aus den Jahren 1433-1437 enthalten nur ganz selten vergleichbar lange Narrationes. Die entsprechenden Formeln sind in der Regel eher kurz und schematisch, wobei sie neben den Petitionsformeln ${ }^{6}$ oft nur stereotype Angaben über Dienste des Empfängers enthalten, die sich gar nicht direkt in der Narratio befinden, sondern erst innerhalb der Dispositio als eine Art eingeschobene Fortsetzung der eigentlichen Narratio.

Trotzdem trat auch hier die skizzierte Memorial-Funktion von Narrationes auf sehr interessante Art und Weise in Erscheinung, was besonders mit dem zu Ende gehenden Hussitenkrieg und dem Abschluss der Kompaktaten sowie der Anerkennung Sigismunds als König von Böhmen in Verbindung gebracht werden kann. König und Kaiser Sigismund war schon seit der Mitte 1420er Jahre der aktivste Propagator von Verhandlungen zwischen den Hussiten und der Kirche, was jedoch nicht hieß, dass er seine antihussitische Rhetorik aufgab (bzw. überhaupt hätte aufgeben können). ${ }^{7}$ Als jedoch die

einem sehr inspirierenden Aufsatz untersucht, auf den hier verwiesen werden kann: Dvořáková, Daniela: Aspekte der Narrationes der Schenkungsurkunden Sigismunds für ungarische Adelige. In: Kaiser Sigismund (1368-1437). Zur Herrschaftspraxis eines europäischen Monarchen. Hg. von Karel Hruza - Alexandra Kaar. Forschungen zur Kaiser- und Papstgeschichte des Mittelalters - Beihefte zu J. F. Böhmer, Regesta Imperii 31. Wien - Köln - Weimar 2012, S. 235-244.

5 Siehe dazu die rezente Untersuchung der (Kanzlei-)Fälschungen Kaspar Schlicks von Elbel, Petr - Zajic, Andreas: Die zwei Körper des Kanzlers? Die „reale" und die „virtuelle“ Karriere Kaspar Schlicks unter König und Kaiser Sigismund - Epilegomena zu einem alten Forschungsthema II. Mediaevalia Historica Bohemica 16/1, 2013, S. 55-212. Im Mittelpunkt dieses Aufsatzes stehen eben die gefälschten Standeserhöhungsurkunden. Über eine umfangreiche Narratio verfügt z. B. die angebliche Freiherrenurkunde für Schlick, die auf den 16. Juli 1422 datiert ist, aber wohl erst 1437 angefertigt wurde - siehe ebd., S. 81-92; Edition bei Elbel, Petr - Zajic, Andreas: Die zwei Körper des Kanzlers? Die „reale“ und die „virtuelle“ Karriere Kaspar Schlicks unter König und Kaiser Sigismund - Epilegomena zu einem alten Forschungsthema III. Mediaevalia Historica Bohemica 16/2, 2013, S. 73-157, hier S. 95-99, Nr. 3, und vor allem die lateinische Ausfertigung der angeblichen Grafenurkunde vom 30. Oktober 1437, die wohl erst im Jahr 1442 gefälscht worden sein dürfte - siehe Elbel, P. - Zajic, A.: Die zwei Körper II, S. 152-176; Edition ebd., S. 134-141, Nr. 15.

6 Zu diesen siehe nun Elbel, Petr: Das Supplikenwesen am böhmischen Hof im Spätmittelalter In: Modus supplicandi. Zwischen herrschaftlicher Gnade und importunitas petentium. Hg. von Christian Lackner - Daniel Luger. Veröffentlichungen des Instituts für Österreichische Geschichtsforschung 72. Wien - Köln - Weimar 2019, S. 93-122.

7 König Sigismund versuchte nach seinen militärischen Niederlagen in Böhmen ziemlich intensiv, Verhandlungen zwischen katholischen und hussitischen Theologen zu vermitteln. Die ersten Treffen scheiterten jedoch entweder völlig (1424 Brünn), oder wurden nur schwach besucht (1425 Brünn und Blindenburg/ Visegrád). Ein großes, repräsentatives Treffen fand erst 1429 in Preßburg statt, wo Sigismund den Hussiten versprach, sie würden zu einem künftigen Konzil eingeladen werden. Ab diesem Zeitpunkt verfolgte Sigismund diese Linie konsequent, obwohl er (eher zum Schein) neue Kriegsaktionen gegen die Hussiten plante bzw. unterstützte. Tatsächlich betrieb er allerdings eindeutig eine Politik der Verhandlungen, die 
vormalige „hussitische Häresie“ durch die Iglauer Kompaktaten zu einem anerkannten Glied der Kirche wurde, änderte sich Sigismunds Verhalten gegenüber der böhmischen Reformation auch nach außen völlig. Dies spiegelt sich notwendigerweise in der Umgestaltung der „offiziellen“ Erinnerung an die Hussitenkriege wider, die u. a. auch durch die Narrationes der kaiserlichen Diplome gestaltet wurde.

Für diesen Beitrag wurden die Narrationes aller bekannten Urkunden Kaiser Sigismunds für böhmische Empfänger aus dem Zeitraum 1433-1437 herangezogen, wobei Urkunden für „katholische“ und „hussitische“ Empfänger getrennt voneinander behandelt werden. ${ }^{8}$

$$
* * *
$$

Sehen wir uns also zunächst die Narrationes der Urkunden für „katholische“ Empfänger an. Am Anfang des hier untersuchten Zeitraumes, d. h. in den Jahren 1433-1434, liefen zwar bereits Verhandlungen zwischen dem Basler Konzil und den Hussiten unter dem Patronat Sigismunds, der Hussitenkrieg spitzte sich jedoch gleichzeitig gefährlich zu, als die radikalen Feldheere die wichtigste katholische Festung in Böhmen, die Stadt Pilsen, etwa ein Jahr lang belagerten, um dadurch die Machtverhältnisse in Böhmen zu ihren

Anfang 1433 in das Eintreffen einer hussitischen Delegation in Basel und den anschließenden Verhandlungsmarathon bis zum Abschluss der Iglauer Kompaktaten im Juli 1436 mündete. Sigismund spielte bei diesen Verhandlungen, die mehrmals zu scheitern drohten, eine Schlüsselrolle. Zur Hussitenpolitik Sigismunds siehe vor allem Kavka, František: Posledni Lucemburk na českém trůnè. Králem uprostřed revoluce [Der letzte Luxemburger auf dem böhmischen Thron]. Praha 1998; Studt, Birgit: Zwischen Kurfürsten, Kurie und Konzil. Die Hussitenpolitik König Sigismunds. In: Sigismund von Luxemburg. Ein Kaiser in Europa. Tagungsband des internationalen historischen und kunsthistorischen Kongresses in Luxemburg, 8.-10. Juni 2005. Hg. von Michel Pauly - François Reinert. Mainz 2006, S. 113-126; Válka, Josef: Sigismund und die Hussiten, oder: wie eine Revolution beenden? In: Kaiser Sigismund. Hg. von K. Hruza - A. Kaar, S. 21-56. Zur Frühphase der Verhandlungen siehe Coufal, Dušan: Polemika o kalich mezi teologii a politikou 1414-1431. Předpoklady basilejské disputace o proním z pražských artikulů [Die Polemik um den Laienkelch zwischen Theologie und Politik 1414-1431. Die Voraussetzungen der Basler Disputation über das erste Prager Artikel]. Praha 2012; zur Endphase Eberhard, Winfried: Der Weg zur Koexistenz: Kaiser Sigmund und das Ende der hussitischen Revolution. Bohemia 33, 1992, S. 1-43; Válka, Josef: Kompaktáta a kapitulace: charta stavovských svobod? [Kompaktaten und Kapitulationen. Die Charta ständischer Freiheiten?] Časopis Matice moravské 129, 2010, S. 19-43. Zur antihussitischen Propaganda in den Urkunden und Briefen Sigismunds, die oft in Gegensatz zu dessen pragmatischer Politik stand, siehe Bar, Přemysl: Protihusitská propaganda v pisemnostech Zikmunda Lucemburského: definice - dochováni - texty [Antihussitische Propaganda in den Schriftstücken Sigismunds von Luxemburg. Definition - Überlieferung - Texte]. Český časopis historický 114, 2016, S. 614-651.

8 Diese Unterscheidung muss jedoch näher präzisiert werden, da es einerseits konfessionell gemischte Städte, andererseits Adelige gab, deren konfessionelle Zugehörigkeit unbekannt oder unklar ist. Dies gilt besonders für die späteren Jahre. Zur Gruppe der katholischen Empfänger werden daher jene Städte und Personen gezählt, die am Beginn des Untersuchungszeitraumes, d. h. vor Entstehung der Koalition des katholischen und utraquistischen Hochadels mit der Prager Altstadt im Frühling 1434, der königlichen Partei angehörten. In dieser Zeit war nämlich eine Zugehörigkeit zur Partei Sigismunds kaum mit einer hussitischen Gesinnung vereinbar. Als hussitische Empfänger werden hingegen jene Städte und Personen betrachtet, die im Jahr 1433 und zu Beginn des Jahres 1434 einer der verschiedenen hussitischen Gruppierungen angehörten. Hier wird die Lage jedoch kompliziert, da etliche katholische Adelige aus Not den hussitischen Bünden beitraten und diese militärisch unterstützten, um ihre Güter zu retten. Auf weitere Aspekte dieser Problematik weist Novotný, Robert: Die Konfessionalität des böhmischen und mährischen Adels in der Zeit der Regierung Sigismunds von Luxemburg. In: Kaiser Sigismund. Hg. von K. Hruza - A. Kaar, S. 57-74, hin. 
Gunsten zu verändern. Die erfolglose Belagerung vertiefte jedoch die Gegensätze innerhalb des hussitischen Lagers, woraufhin im Frühling eine Koalition des hussitischen und katholischen Adels mit der Prager Altstadt entstand, die den radikalen Feldheeren bei Lipany eine verheerende Niederlage beibrachte. Kaiser Sigismund, der zuerst in Italien, dann in Basel und Südwestdeutschland weilte und erst im September 1434 bei einem Aufenthalt in Regensburg in die Nähe Böhmens kam, stellte in dieser Zeit verhältnismäßig wenige Diplome für böhmische Empfänger aus. Die meisten dieser Urkunden wurden eben in Regensburg ausgestellt.

Im Urkundenmaterial dieser Zeit konnte kaum ein Dutzend Urkunden mit Narrationes gefunden werden, die mehr als die Petition und eine kurze Erwähnung der Dienste des Empfängers enthalten. ${ }^{9}$ Es handelt sich dabei um einige vermögensrechtliche Urkunden für Parteigänger Sigismunds, die in der Narratio den finanziellen und rechtlichen Hintergrund der Handlung darlegen, ${ }^{10}$ ein Schutzprivileg für das Augustinerstift zu Glatz/Kłodzko, ${ }^{11}$ drei Privilegienbestätigungen für die katholischen Städte Eger, Brüx

9 Die Erwähnung geleisteter Dienste geschah meist völlig formelhaft in etwa diesem Wortlaut: [...] habentes benignum respectum ad accepta multumque fidelia servicia, nobis et corone regni Boemie per famosum Johannem Sczepanowecz de Wrtba residentem in Waldek, fidelem nostrum dilectum, constanter et fideliter exhibita et futuris temporibus diligencius exhibenda [...] - siehe Sigismundi regis Bohemiae litterae donationum regalium (14211437). 69 listů krále Zikmunda na výprosy v Čechách [Sigismundi regis Bohemiae litterae donationum regalium (1421-1437). 69 Urkunden König Sigismunds aufgrund böhmischer Petitionen]. Hg. von Vojtěch Nováček. Věstník Královské české společnosti nauk. Třída filosoficko-historicko-jazykozpytná 1903. Praha 1904, S. 37, Nr. 48 (1434 September 27, Regensburg). Diese Formel konnte eventuell etwas erweitert werden, z. B. um Angaben, wo genau welche Dienste geleistet worden waren. In den Urkunden Sigismunds für den bayerischen Adeligen Johann von Schönsee, dem der Kaiser einige heimgefallene Güter in Westböhmen schenkte, wurde z. B. der Dienste Johanns in Italien, Deutschland und Böhmen gedacht: [...] attentis et diligenter consideratis acceptis et fidelibus serviciis, quibus maiestati nostre fidelis noster dilectus Johannes de Ssonsee in Ytalie, Alamanie et Bohemie partibus multipliciter placuit et placere debebit et poterit in futurum [...] - siehe Národní archiv [Nationalarchiv] (= NA), Praha, Bestand Desky dvorské [Hoftafeln], Inv. Nr. 25, fol. 208v. Eine solche Erweiterung der Narratio hatte wohl mit einiger Sicherheit vor allem Memorial-Funktion, wobei die Erinnerung an die räumliche Ausdehnung der (militärischen) Dienste Johanns bewahrt werden sollte.

10 Solche Narrationes hatten vor allem rechtliche Bedeutung, da sie nähere Erläuterungen zu dem durch die Dispositio getätigten Rechtsgeschäft enthielten. Trotzdem finden sich auch hier ab und zu diverse memoriale Inhalte. Als Beispiel kann man etwa den am 28. September 1434 in Regensburg ausgestellten Pfandbrief über die Burg und Stadt Elbogen für den Reichshofkanzler Kaspar Schlick nennen, der die Genese und Zusammensetzung der Schulden Sigismunds bei seinem Kanzler genau beschreibt. Zusätzlich wird hier jedoch betont, dass Schlick den Hof Sigismunds in Regensburg durch ein hohes Darlehen von 6.300 rheinischen Gulden „gerettet“ hatte, nachdem der Kaiser infolge des langwierigen Tages mit den Böhmen in finanzielle Nöte geraten war und die Stadt ohne die Hilfe Schlicks kaum hätte verlassen können: [...] Als wir ietzund aus dem heyl. concilio won Basel herkwamen solchen tag, den dann die herren Bo ${ }^{\circ}$ hem hergelegt ha etten, alß um fried und gnad desselbigen landes zu schaffen und mit unß in einigkeit zu kommen, und als un $\beta$ daselbst gro $\beta$ nothdurfft anstiesse, und wir auch mit unserm hoff-gesu ${ }^{\circ}$ nde gro $\beta$ und viel verzehret hetten, also bathen wir den edlen Caspar Slicken, rittern, unßern cantzler, burggraffen zu Eger und besunder lieben getreuen, der un $\beta$ alsdan sechs tausend rheinische gulden und dreyhundert am baaren gelde williglich u $\beta$ un $\beta$ zu grossem danckh liehe und ausreichtet, damit wir dann un $\beta$ und die unsern von hinne fertigten [...] - siehe: Spicilegium seculare des Teutschen Reichs-Archivs [...] II. Hg. von Johann Christian Lünig. Leipzig 1719, S. 1179-1182, Nr. 5, hier S. 1180.

11 In der Narratio dieser Urkunde wird zumindest indirekt auf den noch im Gange befindlichen Hussitenkrieg Bezug genommen, obwohl Hussiten oder Ketzer nicht explizit genannt werden. Die Urkunde erklärt nämlich, dass in den gegenwärtigen schlimmen Zeiten die Bösartigkeit der Menschen zunähme, die 
und Bischofteinitz ${ }^{12}$ und zwei Diplome für die Stadt Pilsen: die Gewährung finanzieller Unterstützung während der erwähnten Belagerung (19. November 1433, Basel) $)^{13}$ und ein umfangreiches Privileg, das die Bürger für die erfolgreiche Verteidigung der Stadt belohnen sollte (19. September 1434 , Regensburg).$^{14}$

Direkte Hinweise auf den - immer noch andauernden - Hussitenkrieg finden sich lediglich in den Urkunden für die Städte. In den Narrationes der drei Privilegienbestätigungen werden die Dienste der einzelnen Stadtgemeinden kurz hervorgehoben, die [...] sy uns und dem reiche und der crone zu Behem, und nemlichen wider die Hussen, die keczer, teglich tund und furbasz tun mogen in kumftigen zeiten. ${ }^{15}$ In der lateinischen Urkunde für Bischofteinitz ist diese Formel um einige Epitheta erweitert, wobei hier grata et fidelia obsequia, nobis et coronae Bohemiae hactenus potissime contra Wiklefistas, nostros et fidei catholicae frivolos et pertinaces adversarios, constanter impensa gewürdigt werden. ${ }^{16}$ Daneben ist hier auch die gängige Arenga Etsi regie dignitatis benigna sublimitas etwas modifiziert, indem betont wird, dass der Kaiser besonders jenen Personen Gnade erweisen soll, die ampliori devotionis et fidei constantia circa nos et praedecessores nostros et signanter istis temporibus Wiklefistarum haereticorum insultibus et eorum frivolis machinamentis fortiter resistendo prae ceteris claruisse. ${ }^{17}$

Eine etwas detailliertere Narratio findet sich in der ersteren Urkunde für Pilsen vom November 1433, in der die Leiden der Pilsner während der jüngsten Belagerung der Stadt thematisiert, sowie ihre feste Treue dem katholischen Glauben und Kaiser Sigismund gegenüber betont werden. ${ }^{18}$ Diese Urkunde lässt sich jedoch keineswegs mit dem

deswegen die Glatzer Chorherren und deren Untertanen im Gegensatz zu ihren Gnaden und Freiheiten belästigten - siehe NA Praha, Bestand České gubernium - listiny [Böhmisches Gubernium - Urkunden], Inv. Nr. 3011, fol. 21r-23r.

12 Alle drei Städte hatten schon zuvor Privilegienbestätigungen von Sigismund als böhmischem König erhalten; nach der Kaiserkrönung im Mai 1433 ließen sie sich ihre Privilegien unter dem kaiserlichen Siegel neuerlich bestätigen (und teils auch vermehren). Die Urkunde für Eger vom 22. Februar 1434, Basel in Codex iuris municipalis regni Bohemiae (= CIM). III. Privilegia regalium civitatum provincialium annorum 1420-1526. Ed. Jaromír Čelakovský - Gustav Friedrich. Praha 1948, S. 89-92, Nr. 62; die Urkunde für Brüx vom selben Tag ist in CIM III, S. 92, Nr. 63, nur regestiert, siehe daher Schlesinger, Ludwig: Stadtbuch von Brüx bis zum Jahre 1526. Beiträge zur Geschichte Böhmens. Abteilung IV. Städte-Bücher 1. Prag - Leipzig - Wien 1892, S. 101-102, Nr. 225. Die Privilegienbestätigung für Bischofteinitz vom 12. März 1434 in CIM IV-1. Privilegia non regalium civitatum provincialium annorum 1232-1452. Ed. Antonín Haas. Praha 1954, S. 353-354, Nr. 246, wo aber nur ein Regest gegeben wird, bei dem der Herausgeber auf die ältere Privilegienbestätigung für dieselbe Stadt verweist, die an der entsprechenden Stelle im Volltext unter Auszeichnung der Unterschiede zur Urkunde vom Jahr 1434 abgedruckt ist - siehe ebd., S. 339-340, Nr. 232.

13 Siehe die Abschrift in Haus-, Hof- und Staatsarchiv Wien (=HHStA Wien), Reichsregister (= RR) K, fol. 51r-v (alt: 41r-v); Kurzregest in J. F. Böhmer, Regesta Imperii. XI. Die Urkunden Kaiser Sigmunds 1410-1437. 2. 1425-1437 (= RI XI-2). Hg. von Wilhelm Altmann. Innsbruck 1897-1900, S. 256, Nr. 9825.

14 Edition in CIM III, S. 93-100, Nr. 64.

15 CIM III, S. 90. In der Urkunde für Brüx leicht abweichend: die [...] sy uns und dem riche und der cron zu Behem und nemlichen wider die Hu essen die keczer teglichen tu ${ }^{e}$ und sich bißher mit grosser mu ${ }^{e} e$ und coste vesticlich gehalten haben und hinfu er zu tun willig sein [...] - siehe Schlesinger, L.: Stadtbuch, S. 102.

16 CIM IV-1, S. 339.

17 Ebd.

18 Quemadmodum ad presens fideles nostri dilecti cives et civitas Pilsniensis per nephandos hereticos Bohemie circumvallati et obsidione circumdati magnos insultus ac gravissima incommoda paciuntur [PE: hier folgt eine Darstellung der 
nächsten, im böhmischen Urkundenmaterial Sigismunds völlig singulären Privileg für Pilsen vom September 1434 vergleichen, das mit einer Goldbulle besiegelt wurde. ${ }^{19}$

Allein inhaltlich ist dieses Stück völlig außergewöhnlich, da der Stadt eine ewige Befreiung von der königlichen Steuer sowie von allen Zöllen, Mauten, Brückenzöllen und Abgaben in Böhmen und im ganzen Reich gewährt wurde. Hier interessiert uns jedoch vor allem die bemerkenswerte Narratio, die schon durch Länge und Stil eher in den Kontext der oben erwähnten ungarischen Narrationes gehört. Sie beginnt mit einer umfangreichen Einführung in die Geschichte der wiklifitischen Sekte der „verdammten Ketzer" Johannes Hus und Hieronymus und ihrer zahlreichen Verbrechen. Zu diesen gehörten auch die wiederholten Belagerungen der Stadt Pilsen, deren letzte besonders lang und grausam gewesen sei. Die Pilsner hätten diese Belagerung vor allem dank ihrer Tugenden erfolgreich überstanden, die mit dem üblichen Vokabular der ungarischen Narrationes gepriesen werden. ${ }^{20}$ Die Empfänger seien zwar als bloße Bürger geboren, ihre Tugenden hätten sie jedoch geadelt und ihr Glaubenseifer mit der Ritterwürde Christi geehrt. Trotz des unvorstellbaren Leids und des Hungers in der Stadt, die besonders ausdrucksstark beschrieben werden, hätten sie letztlich mit Gottes Hilfe die „Häretiker“ derart zu Boden gerungen, dass der Name Pilsens, der für diese beherzten und treuen Taten von frommen Christen auf ewig gepriesen werden sollte, stets einen bitteren Geschmack in der Kehle der „Häretiker“ zurücklassen werde.

Die lange Narratio dieser Urkunde sollte sicherlich einerseits die weitrechenden Bestimmungen der Dispositio entsprechend begründen, andererseits aber auch eine „offizielle" Fixierung der Memoria an die Belagerung von Pilsen durch den Kaiser sanktionieren. Als solche wurde diese Narratio später auch häufig verwendet, was auch durch eine alttschechische Übersetzung der Urkunde erleichtert wurde. ${ }^{21}$ Zitate aus der Narratio finden sich in der humanistischen und barocken Stadtgeschichtsschreibung, in der die Urkunde immer wieder abgeschrieben wurde..$^{22}$ Daneben entstanden zahlreiche Konfirmationen durch einzelne Herrscher, die eindeutig aus rechtlichen Gründen beschafft wurden. Im Nachleben der Urkunde lassen sich somit zwei Traditionen unterscheiden,

Pilsner Gesandtschaft nach Basel, die den Kaiser und das Konzil um finanzielle Unterstützung bat] propter eorum firmam constanciam ac laudabilem perseveranciam, quas gesserunt atque gerunt erga fidem catholicam et nos ipsorum dominum naturalem [PE: hier folgt die Dispositio, in welcher der Aussteller versprach, 4.000 rheinischen Gulden in vier Raten auszubezahlen] - HHStA Wien, RR K, fol. 51r (alt: 41r).

19 Mit der Urkunde beschäftigte sich jüngst vor allem Kaar, Alexandra: Die stadt (...) viel privilegirt, aber wenig ergötzt. Sigismunds Herrschaftspraxis und seine Urkunden für die „katholischen “ königlichen Städte Böhmens. In: Kaiser Sigismund. Hg. von K. Hruza - A. Kaar, S. 267-300, hier 278, 287-289; Malivánková Wasková, Marie - Douša, Jaroslav u. a.: Dějiny města Plzně. 1. Do roku 1788 [Geschichte der Stadt Pilsen. 1. Bis zum Jahr 1788]. Plzeň 2014, S. 209, 240-241.

20 Die Urkunde bezeichnet die Pilsner z. B. als fidei tetragonos immobiles et fideles. Zum Verwendung des Begriffs tetragonus in den Narrationes der ungarischen Urkunden Sigismunds siehe Dvořáková, D.: Aspekte, S. 242-243.

21 Siehe dazu Liška, Raimund: České překlady zlaté bully cís. Zikmunda udělené Plzni r. 1434 [Tschechische Übersetzungen der goldenen Bulle Kaiser Sigismunds für Pilsen]. In: Sborník městského historického musea císaře a krále Franitška Josefa I. v Plzni 3. Plzeň 1914, S. 33-45, mit der Edition auf S. 36-45.

22 Siehe vor allem M. Šimona Plachého z Třebnice Paměti Plzeňské [M. Simon Plachýs von Trebnitz Pilsner Denkwürdigkeiten]. Hg. von Josef Strnad. Plzeň 1883, S. 21-28. 
wobei erstere hauptsächlich auf die Narratio und den übrigen Urkundentext als Träger der städtischen Memoria, zweitere auf die Dispositio und den Rechtsinhalt des Stücks als Garanten der städtischen Steuer- und Zollfreiheit fokussierte.

Die bemerkenswerte Goldene Bulle für Pilsen stellt allerdings den letzten Fall einer derart detaillierten Narratio für einen katholischen Empfänger in Böhmen dar. Vom Herbst 1434, dem ganzen Jahr 1435 und der ersten Jahreshälfte 1436 gibt es jedenfalls nur wenige Urkunden Sigismunds für böhmische Empfänger.

$$
* * *
$$

Diese Situation änderte sich nach der Anerkennung Sigismunds als König von Böhmen durch die utraquistischen Stände im Sommer 1436. Die anschließende „Flut“ kaiserlicher Urkunden aus den Jahren 1436/37 hatte jedoch hauptsächlich Utraquisten, mit denen Sigismund nun einen modus vivendi finden musste (siehe dazu weiter unten), zum Empfänger. Die katholischen Städte und Adeligen traten in den Hintergrund, was sie oft schlecht aufgenommen haben dürften. ${ }^{23}$ Die Wende des Sommers 1436 spiegelt sich in den Narrationes der Urkunden Sigismunds sehr deutlich wider. Die Utraquisten, die nun offiziell als Angehörige der katholischen Kirche galten, konnten in den Urkunden nicht mehr als Wiklifiten, Hussiten und Ketzer bezeichnet werden, was aber offensichtlich auch in die Vergangenheit zurückprojiziert wurde. Sehen wir uns jedoch zunächst Sigismunds Urkunden für katholische Empfänger an.

Die meisten Narrationes begnügen sich mit der Erwähnung der ständigen Treue des Empfängers dem Kaiser gegenüber und ggf. auch der Petitio. ${ }^{24}$ Wird die Natur dieser Treue näher erläutert - was nur selten der Fall ist - werden lediglich die „vorangegangenen Unruhen und Kriege im Königreich Böhmen“ erwähnt, in welchen der Empfänger stets auf Seiten des Kaisers gestanden sei und dabei zahlreiche Schäden erlitten habe. Wohl am ausführlichsten in diesem Zusammenhang ist die Narratio der Goldenen Bulle für Eger vom 25. Januar 1437, in welcher wir u. a. lesen, dass die Egerer sich in disen kriegen und zwileufen des kunigrichs zu Behem so trefflich angriffen und leib und gut so costbarlich dargelegt habenn bey uns und unserm teil, das uns das gen in nit zu vergessen, sunder alczeit gnediclich zu gedencken ist. ${ }^{25}$ Ähnliches lesen wir auch in einem Pfandbrief für Pilsen vom Dezember 1436, ${ }^{26}$ oder in Urkunden für Kaaden ${ }^{27}$ bzw. Tachau, in denen zudem

23 Dies illustrieren z. B. die sehr komplizierten Beziehungen zwischen Sigismund und dem mächtigsten böhmischen Magnaten Ulrich von Rosenberg, welcher bereits im Sommer 1420 zum katholischen Glauben und König Sigismund übergetreten war und seither der wichtigste Vertreter der Sigismund-Partei in Böhmen war. Seinen deutlichen Bedeutungsverlust in den Jahren 1436/37 nahm er sehr schlecht auf, was sich in fast kontinuierlichen Spannungen zwischen ihm und dem Herrscher äußerte. Zu diesen Spannungen siehe Kubíková, Anna: Oldřich II. z Rožmberka [Ulrich II. von Rosenberg]. České Budějovice 2004, S. 77-82.

24 Zum (Nicht-)Vorhanden sein der Petitio vgl. Elbel, P.: Das Supplikenwesen, S. 98-99, 104-108.

25 CIM III, S. 163-167, Nr. 101, hier S. 164.

26 CIM III, S. 147-148, Nr. 94, hier S. 147: [...] znamenajice mnohá zachováni opatrných purgmistra a konšeluov $i$ vši obce města Nového Plzně, věrných našich zvláště milých, jimižto jsú se všecka létha jminulá naši velebnosti, žádnými pritkami odhroziti se nedavše, stále přidrželi i ještě se přidrži a v časech budúcích přidržeti se maji, pozorujíce také, že pro víry své ustavičnost $k$ nám obležením i jinými náklady ke škodám a dluhuom velikým př̀̌̌li [...].

27 CIM III, S. 152-153, Nr. 97, hier S. 152: [...] attendentes et benigne considerantes fidelia obsequia fidelium 
festgehalten wird, dass die städtischen Privilegien in den vergangenen Unruhen vernichtet worden seien. ${ }^{28}$ Die (Reichs-)Hofkanzlei vermied jedenfalls in den Narrationes konsequent jede Erwähnung von Hussiten, oder deren - auch nur retrospektive - Bezeichnung als Ketzer bzw. Hussiten.

Da der lange Kampf gegen die „hussitische Häresie“ mittlerweile zum integralen Bestandteil der Identität der katholischen Städte Böhmens und Mährens geworden war, wie das Beispiel Pilsen am besten zeigt, was aber bestimmt auch auf Eger, Budweis, Brüx, oder die mährischen katholischen Städte zutraf, dürfte die veränderte Rhetorik der kaiserlichen Diplome dort nicht gerade begrüßt worden sein. Nachdem die kaiserliche Kanzlei sich zunehmend unwillig zeigte, den treuen Kampf der Empfänger gegen die „hussitischen Ketzer“ gebührend hervorzuheben, gingen die katholischen Städte dazu über, sich diese Memoria durch andere Autoritäten fixieren zu lassen. Ein besonders aufschlussreiches Beispiel stammt aus der mährischen Bischofsstadt Olmütz, die kurz vor dem Iglauer Tag, am 31. Mai 1436, vom Olmützer Domkapitel eine bemerkenswerte Urkunde erhielt. ${ }^{29}$ Formal gesehen handelte es sich um ein Empfehlungsschreiben für die Olmützer Bürger bei allen geistlichen und weltlichen Fürsten sowie allen treuen Christen. Den Kern dieser Urkunde bildet jedoch die lange Narratio, die die Übeltaten der Wiklifiten und Hussiten ausdrucksstark schildert ${ }^{30}$ und die Schäden, die die Olmützer Bürger durch die Hussiten erlitten hatten, näher beschreibt. ${ }^{31}$ In der Dispositio fordern die Aussteller alle Christen auf, die Olmützer als fortes atthletas in agone certaminis perseverantes et constantes filios obediencie sancte matris Romane ecclesie katholicos et fidei orthodoxe zu betrachten, qui nec rebus nec corporibus usque ad extenuacionem fere extremam propter fidem katholicam nullo modo pepercerunt. ${ }^{32}$ Die Urkunde diente den Empfängern wohl nicht so sehr als Empfehlungsschreiben, sondern vielmehr als offizielle Bestätigung der städtischen Erinnerung an den langwierigen Kampf gegen die „hussitische Häresie“, 33

nostrorum civium civitatis Cadanensis nobis et corone regni Bohemie exhibita nec non gravia dampna, que iidem cives in disturbio gwerrarum regni Bohemie sunt perpessi $[\ldots]$.

28 CIM III, S. 125-128, Nr. 80, hier S. 126: [...] in hiis disturbiis regni Bohemie malignorum insolencia excrescente suis privilegiis, iuribus et libertatibus, eis a predecessoribus et progenitoribus nostris dive memorie concessis, sunt orbati $[\ldots]$.

29 Siehe dazu Roubic, Antonín: Olomouc a basilejský koncil. Husitský Tábor 8, 1985, S. 133-144, mit dem Abdruck des Stückes auf S. 142. Einige Fehler in dieser Edition müssen anhand der Originalurkunde in Zemský archiv v Opavě [Landesarchiv Troppau] - Státní okresní archiv Olomouc [Staatsbezirksarchiv Olmütz], Bestand Archiv města Olomouce [Stadtarchiv Olmütz], Urkunden, Inv. Nr. 147 verbessert werden.

30 [...] et post mortem ipsius [PE: König Wenzels] orta dudum secta et perfidia dampnatorum Johannis Wicleph et Johannis Hus in flammam horribilem exalavit et persecucio dura et horribilis ac tirannica per sectatores eorundem in omnes katholicos et fidei orthodoxe Regni Boemie et marchionatus Morauie et in omnes regiones vicinas crudeliter emanavit - siehe ebd.

$31[\ldots]$ in hanc autem civitatem Olomucensem iam dictam tamquam in caput marchionatus Morauie anthomasice [!] crudelius ac sevius exarserunt eandem devastantes continue in omnibus rebus temporalibus usque ad muros et circumsepientes eam ex omnibus partibus gentibus crudelissimis et perniciosis et municionibus fortissimis tamquam in vicinatu positis, quas per tyrannidem in katholicis acquisierunt. Ita quod a tamporibus illis usque ad tempus presens, que quantitas temporis se extendit fere usque ad viginti annos non dabatur requies civitati antedicte die ac nocte a talibus oppressionibus et devastacionibus inhumanis - siehe ebd.

32 Ebd.

33 Roubic, A.: Olomouc a basilejský koncil folgend, könnte man dieses Empfehlungsschreiben wohl auch als 
die darüber hinaus auch in einigen historischen Texten des Stadtschreibers Wenzel von Iglau in dem durch diesen begründeten Olmützer Stadtbuch fixiert wurde. ${ }^{34}$

$$
* * *
$$

Wie sahen nun die Narrationes der Urkunden Sigismunds für utraquistische Städte und Adelige aus den Jahren 1436-1437 aus?35 Während wir bei den Katholiken beobachten konnten, dass das Andenken an deren Treue und im „vergangenen Krieg“ erlittene Schäden weiterhin hervorgehoben wurde und lediglich die nähere Bezeichnung des Feindes und die früher übliche Darstellung von dessen Übeltaten unterblieb, stand die (Reichs-) Hofkanzlei bei den Utraquisten vor einer ungleich schwierigeren Aufgabe. Die Narratio

eine Art „Manifest“ der Stadt und des Domkapitels von Olmütz für den bevorstehenden Iglauer Tag betrachten, auf dem die Olmützer Gesandtschaft sich einerseits mit diesem Schreiben bei den dort anwesenden katholischen Autoritäten „ausweisen“ und andererseits den Olmützer Unwillen gegen die Kompaktaten zum Ausdruck bringen konnte. Diese Annahme lässt sich jedoch quellenmäßig nicht direkt belegen.

$34 \mathrm{Zu}$ den historiographischen Texten Wenzels siehe Loserth, Johann: Historische Aufzeichnungen aus der Hussitenzeit des Stadtschreibers Wenzel von Iglau. Mitteilungen des Vereines für die Geschichte der Deutschen in Böhmen 19, 1880-1881, S. 81-89. Eine kritische Edition von Wenzels Stadtbuch wurde in Památná kniha olomoucká (kodex Václava z Jihlavy) z let 1430-1492, 1528. Hg. von Spáčilová, Libuše - Spáčil, Vladimír. Olomouc 2004, vorgelegt. Wenzels historiographische Texte behandeln für die Hussitenzeit die Anfänge des Hussitismus in Prag und die Verbrennung zweier Prager Studenten in Olmütz im Jahr 1415 (ebd., S. 205-206, Nr. 49), den Olmützer Bistumsstreit der Jahre 1416-1420, den Wenzel mit der Verbreitung des Hussitismus in Mähren in Zusammenhang bringt (siehe ebd., S. 217-218, Nr. 69), die schwierige Lage der Stadt während des Hussitenkriegs (ebd., S. 231, Nr. 100) und die Eroberung des nahegelegenen Littau durch die Reste der radikalen Hussitenheere sowie die rasche Rückeroberung derselben Stadt durch das städtische Olmützer Aufgebot im Herbst 1437 (ebd., S. 209-210, Nr, 53). Danach folgen kurze Nachrichten über den Tod Kaiser Sigismunds und die Wahl Herzog Albrechts V. von Österreich zum ungarischen, böhmischen und römischen König (ebd., S. 211, Nr. 55) sowie über den baldigen Tod Albrechts (ebd., S. 211-212, Nr. 56). Von den erwähnten Passagen ist hier vor allem Wenzels Darstellung der schwierigen Lage der Stadt während des Kriegs von Interesse, da dort ähnlich wie in der zitierten Urkunde des Domkapitels vom Mai 1436 die Standhaftigkeit der Bürger im Kampf gegen die Hussiten trotz der Einkesselung durch zahlreiche hussitische Festungen hervorgehoben wird: [...] necnon et cives eiusdem Olomucensis civitatis decursu temporum pregravati ad resistendum eorum emulis et presertim istis quamplurimum annorum curriculis, quibus sediciosa perniciosum hereticorum in regno Bohemiae et marchionatu Moravie degebat temeritas [...] Et quia ipsa civitas Olomucensis utputa capitalis urbs Morauie et orthodoxorum congeries a primitivis horum nephandorum iniciis hereticorum se viriliter ingesserit [...] Et demum contra ceteros suis propriis sumptibus et stipendiis largibus innumerum populum bellicaliter in regnum Bohemie ad succursum civitatibus ibidem Christi fidelium destinare procurarunt ac aliis municionibus in Morauia succurere seseque tueri a iugibus attemptacionibus illorum emulorum, que in marchionatu Morauie utputa Thowaczaw, Chremsir, Preraw, Magetin, Namyesscz, Vniczow, Hluboky, Sowynecz, Bistrzicz, claustro Redisch, Skrbin, Horka, Tribouia et aliis quam plurimis circum civitatis ubique in universis quasi castris et locis degebant, die noctuque civitati Olomucensi insidias ponendo necessabantur (ebd., S. 231). Im bewussten Kontrast zum dichten Netz der hussitischen Orte rund um die Stadt führt Wenzel an anderer Stelle an, die nächsten Verbündeten von Olmütz seien die Städte Littau, Brünn, Ungarisch Hradisch, Troppau und Jägerndorf gewesen. Mit Ausnahme von Littau sind alle diese Orte 70-80 km von Olmütz entfernt: Quia tantus in hominibus erat timor et tremor, quod quasi omnis populus eis [PE: den Hussiten] adherere compellebatur. Ita quod in hoc confinio hec Olomucensis civitas solum Luthouia, Redisch, Brunnam, Oppauiam et Carnouiam propinquiores habebat amicicie vicinos (ebd., S. 205).

35 Aus der Zeit vor Juli 1436 gibt es so gut wie keine Urkunden Sigismunds für hussitische Adelige und Städte, mit Ausnahme von Geleitsbriefen zu politischen Treffen und den sog. kaiserlichen Kompaktaten. Diese Dokumente sind für unser Thema wenig interessant, da sie - mit der Ausnahme der Ausfertigung der kaiserlichen Kompaktaten für die Prager Alt- und Neustadt, die eine detaillierte Petition anthält (CIM I. Privilegia civitatum Pragensium. Hg. von Jaromír Čelakovský. Praha 1886, S. 216-219, Nr. 134) keine längeren Narrationes enthalten. 
konnte nämlich meist beim besten Willen keine treuen Dienste des Empfängers dem Herrscher gegenüber hervorheben, es sei denn, er hatte sich um die Verhandlungen über die Kompaktaten und die Anerkennung Sigismunds als König von Böhmen in den Jahren 1433-1436 verdient gemacht. Die meisten utraquistischen Empfänger konnten jedoch keine treuen Dienste Sigismund gegenüber vorweisen.

Dieser Mangel wurde in den Narrationes meist dadurch gelöst, dass die Kanzlei die übliche Anerkennung der treuen Dienste des Empfängers als in die Zukunft gerichtete Erwartung formulierte. Dies war in Kaiserurkunden keine unbekannte Lösung; sie kam üblicherweise dann zur Anwendung, wenn der Empfänger dem Aussteller aus begreiflichen Gründen noch keine Dienste hatte leisten können (da er z. B. gerade erst mündig geworden oder zum Bischof gewählt worden war). In solchen Stücken wurde betont, der Aussteller ziehe bei der Erteilung der Urkunde in Betracht, dass der Empfänger ihm in Zukunft wichtige Dienste leisten könne und werde. ${ }^{36}$ Diese Formulierung kam in den Urkunden für utraquistische Empfänger massiv zur Anwendung, wobei sie auch noch weiterentwickelt wurde. In der Narratio lesen wir dann in der Regel, Kaiser Sigismund habe den Eifer des Empfängers bemerkt, welcher ihm und der Böhmischen Krone künftig sehr nützliche Dienste leisten könne. Sigismund wolle ihn gnädig behandeln, damit er dem Herrscher umso besser dienen und umso mehr zum Gemeinwohl beitragen könne. ${ }^{37}$ Die ganze Urkunde verströmt den Wunsch des Herrschers, sich durch ihre Ausstellung die Loyalität des Empfängers abzusichern, was oft nicht weit von der Wahrheit entfernt gewesen sein dürfte..$^{38}$

Bei manchen utraquistischen Empfängern konnten daneben auch treue Dienste ihrer Vorfahren hervorgehoben werden. Dies galt vor allem für die Städte, wo Sigismund in den Narrationes an die traditionelle Treue und Ergebenheit der fraglichen Städte den böhmischen Königen gegenüber anknüpfen konnte. Damit bewegen wir uns endlich (wieder) im Bereich der Erinnerung, obwohl es sich um eine Erinnerung an vorhussitische Zeiten handelt, in welcher die Empfänger Vorbilder für ihr künftiges Verhalten suchen sollten.

36 Siehe z. B. die Privilegienbestätigung Kaiser Friedrichs III. für den erwählten und bestätigten Erzbischof Eberhard von Salzburg vom 9. Juni 1466, Wiener Neustadt. Der Aussteller beruft sich auf die treuen Dienste der früheren Erzbischöfe von Salzburg ihm, seinen Vorgängern und dem Reich gegenüber, sowie auf die zu erwartenden Dienste des Empfängers: Des haben wir angesehen und guttlich betrachtet [...] und auch gneme, nuczlich und getrew dinste, die sein vordern ertzbischoven zu Saltzburg unnsern vorfaren am reiche Romischen keysern und kunigen, auch uns und dem reiche offt und dicke williclich getan haben und der benant bestett uns und dem reiche wol tun mag und sol in kunfftigen zeitten - HHStA Wien, Allgemeine Urkundenreihe 1466 VI 9.

37 [...] znamenav̌še pilnost slovutného Jana Chotunye z Nestiegiowa, věrného našeho milého, a že nám a tej coruně našie czeske dobře slúżiti muože, my chtiece s ním milostivě nakládati, aby sě nám $k$ zemskému dobrému a $k$ službě tiem lépe hoditi mohl [...] - Archiv města Plzně [Stadtarchiv Pilsen], Bestand Sbírka cizích listin [Sammlung fremder Urkunden], Kart. 8, Inv. Nr. 831, Sign. I.123 (1436 September 21, Prag). Siehe dazu die Analyse des Formulars der tschechischen Pfandbriefe Sigismunds bei Bárta, Stanislav: Zástavní listiny Zikmunda Lucemburského na církevni statky (1420-1437) [Die Verpfändungsurkunden Sigismunds von Luxemburg über die kirchlichen Güter (1420-1437)]. Spisy Filozofické fakulty Masarykovy univerzity - Opera Facultatis philosophicae Universitatis Masarykianae 457. Brno 2016, S. 78-84, zur Narratio S. 79-80.

38 Siehe z. B. die Ausführungen Bártas über Pfandbriefe als Instrumente zur Stabilisierung der politischen Lage in Böhmen - ebd., S. 84-90. 
Die Erinnerung an die hussitische Revolution wurde in den Urkunden für utraquistische Empfänger dagegen möglichst unterdrückt. Obwohl der Kaiser den vergangenen Widerstand und den religiösen Ungehorsam der Empfänger sowie die anschließende Aussöhnung mit dem Herrscher und der Kirche hätte erwähnen können, bevorzugte er es, die Revolution zu verschweigen, so als ob es sie nie gegeben hätte.

Wenn in den Narrationes vereinzelter Urkunden für utraquistische Empfänger der Hussitenkrieg trotzdem erwähnt wird, geschieht dies in der Regel im Zusammenhang mit der Darstellung der durch den Krieg verursachten Schäden, sodass die Empfänger - meist handelt es sich um Städte - eigentlich als Opfer der vorangegangenen Wirren erscheinen. ${ }^{39}$ Inhaltlich vergleichbar wird gelegentlich auch betont, dass der Krieg die Empfänger um ihre legitime Herrschaft gebracht hätte, wodurch sie des notwendigen Schutzes entbehrten - was sich unter Sigismunds Herrschaft nun ändern werde. ${ }^{40}$

Diese aufgrund eines ziemlich breiten Urkundenkomplexes formulierten Beobachtungen lassen sich anhand einiger aufschlussreicher Beispiele näher illustrieren. Das dabei wohl interessanteste, gleichzeitig aber nicht unbedingt der Norm entsprechende Beispiel stellt der Urkundenkomplex für die Prager Altstadt dar, der am 26. August 1436 - drei Tage nach dem feierlichen Einzug Sigismunds in die Hauptstadt und am Tag der feierlichen Huldigung des Königs durch die Prager Bürger - entstand. ${ }^{41}$

Diese vier Urkunden sind nur abschriftlich überliefert. Im Staatsarchiv Wittingau finden sich jedoch ausführliche Regesten, die im Unterschied zu den lange bekannten

39 Siehe z. B. die Urkunde Sigismunds für die Stadt Kaurim vom 18. Dezember 1436: [...] considerantes magna et gravia dampna atque dispendia, que fideles nostri dilecti .. magister civium, consules, cives et communitas civitatis nostre Gurim propter guerrarum discrimina in regno nostro Bohemie preterito tempore vigencia perceperunt, pensantes eciam ipsorum diligenciam, qua nobis et regno nostro Bohemie placent et placere poterunt in futurum [...] - CIM III, S. 143, Nr. 92.

40 Siehe in diesem Zusammenhang z. B. das Privileg für Böhmisch Brod vom 4. Februar 1437: [...] pro parte civium civitatis Boemicalis Brode humili narracione est propositum nostre maiestati, qualiter ipsi et eorum civitas una cum possessionibus et pertinenciis universis per multa annorum volucra domino legitimo gubernatore ac protectore destituti quam plurima dampna personarum et rerum ferme irrecuperabilia pertulerunt et assidue perferre coguntur, et nisi in dicionem, proteccionem et proprietatem nostram regiam subito fuerint graciose assumpti, perpetuo et irremediabili una cum sua civitate asserebant se subituros defectu [...] - CIM III, S. 181-182, Nr. 108.

41 Zu diesem Einzug siehe Čornej, Petr: Skrytý význam politické podívané: Zikmundův př́jezd do Prahy 23. srpna 1436 [Die verborgene Bedeutung des politischen Spektakels: Sigismunds Einzug nach Prag am 23. August 1436]. In: Ders.: Světla a stíny husitství. Události, osobnosti, texty, tradice. Výbor z úvah a studií. Praha 2011, S. 186-197; Borovský, Tomáš: Adventus regis in unruhigen Zeiten. Sigismund und die Städte in Böhmen und Mähren. In: Kaiser Sigismund. Hg. von K. Hruza - A. Kaar, S. 367-384, hier S. 378-380; Bláhová, Marie: Ceremoniály a rituály restituce královské moci v pohusitských Čechách. Pobyt Zikmunda Lucemburského v Praze v letech 1436-1437 v soudobé historiografii [Die Zeremonielle und Rituale der Restitution der königlichen Macht im nachhussitischen Böhmen. Der Aufenthalt Sigismunds von Luxemburg in Prag in den Jahren 1436-1437 in der zeitgenössischen Historiographie]. In: Ecclesia - Regnum - Fontes. Studia z dziejów średniowiecza. Hg. von Sławomir Gawlas - Katarzyna Gołąbek - Marek A. Janicki - Roman Michałowski- Marta Piber-Zbieranowska - Piotr Węcowski. Warszawa 2015, S. 217-227, hier S. $222-223$. Bisher unbekannte Quellen zu diesem Ereignis in der Form von Depeschen einer in Prag anwesenden mantuanischen Gesandtschaft entdeckte E. Kovács, Péter: Der Bericht Simone da Cremas, des Botschafters von Mantua, über den Prager Einzug Sigismunds. Studia mediaevalia Bohemica (in Druckvorbereitung); populärwissenschaftlich, jedoch sehr zutreffend Novotný, Robert: Dvě Zikmundovy korunovace [Die zwei Krönungen Sigismunds]. Dějiny a současnost 40/2, 2018, S. 14-17. 
Registereinträgen und anderen Kopien die äußere Form der Stücke näher beschreiben, sodass wir uns ihr Aussehen besser vorstellen können.

Die erste Urkunde (A) war ein feierliches Diplom mit Monogramm und Signumzeile, das mit Goldbulle besiegelt wurde und eine allgemeine Privilegienbestätigung und die Konfirmation zweier wichtiger Privilegien Kaiser Karls IV. enthielt. ${ }^{42}$ Die zweite Urkunde (B) war ein einfaches Diplom unter kaiserlichem Münzsiegel, das allerdings in Libellform ausgefertigt wurde und die Konfirmation von weiteren 18 Urkunden enthielt, die Sigismund im Original vorgelegt worden waren. ${ }^{43}$ Die dritte Urkunde $(\mathrm{C})$ wurde ebenfalls in Libellform ausgefertigt und mit dem Münzsiegel versehen und enthielt die Erneuerung von 12 Urkunden, die Sigismund nur mehr als Abschriften in antiquis registris vorgelegt werden konnten, da die Originale im vorangegangenen Krieg verloren gegangen waren. ${ }^{44}$ Die vierte Urkunde (D) wurde als ein einfaches Diplom expediert und enthielt die Bestätigung einer Urkunde König Wenzels IV. ${ }^{45}$

Schon die äußere Form dieser Urkunden muss bei der Aushändigung an die Empfänger imposant gewirkt haben. In den Böhmischen Ländern gibt es sonst keine vergleichbare Urkundengruppe Sigismunds für eine Stadt. Diese Urkunden weisen jedoch auch sehr interessante Narrationes auf, wobei das Stück A sogar eine spezielle Prager Arenga besitzt, die die Sonderstellung der Stadt unter den anderen königlichen Städten hervorhebt, dank derer Prag die besondere Aufmerksamkeit des Herrschers verdiene. ${ }^{46}$ Die Wurzeln dieser Arenga reichen tief in das 14. Jahrhundert zurück. ${ }^{47}$

Die Narrationes der einzelnen Stücke sind teilweise unterschiedlich aufgebaut, wobei man insgesamt drei Elemente unterscheiden kann. In A werden die Dienste hervorgehoben, die die Altstädter Bürger Kaiser Sigismund und dem Königreich Böhmen schon erwiesen hatten und in Zukunft noch erweisen würden, so sie sich ausreichend durch

42 Siehe CIM I, S. 221-224, Nr. 137. Die dort unberücksichtigten Wittingauer Regesten in Státní oblastní archiv v Třeboni [Staatliches Gebietsarchiv Wittingau] (= SOA Třeboň), Bestand Historica Třeboň, Sign. 333 I, fol. 42r-v; Sign. 333 II, fol. 45r-v.

43 CIM I, S. 228-229, Nr. 140; vgl. die Regesten in SOA Třeboň, Bestand Historica Třeboň, Sign. 333 I, fol. 18r-23v; Sign. 333 II, fol. 14v-23v.

44 CIM I, S. 224-226, Nr. 138; vgl. die Regesten in SOA Třeboň, Bestand Historica Třeboň, Sign. 333 I, fol. 23v-27r; Sign. 333 II, fol. 21v-26r.

45 CIM I, S. 226-227, Nr. 139; vgl. die Regesten in SOA Třeboň, Bestand Historica Třeboň, Sign. 333 I, fol. 34r-v; Sign. 333 II, fol. 35v-36v (beide mit falschem Datum 1437 August 31).

46 Et si imperialem regalemque decet sublimitatem paci et quieti omnium intendere et sua unicuique iura in statu solido conservare, specialius tamen innata nobis clemencia et regni auctoritas nos ammonet ac quadam prerogativa favoris et gracie et solito nostre benignitatis more menti nostre insidet, qualiter nostre celsitudinis providencia civitatis nostre hereditarie et peculiaris Pragensis, que quia sedes et caput regni nostri Bohemie existit omnesque alias civitates eiusdem precellit excellencie dignitate, necnon civium eiusdem, fidelium nostrorum dilectorum, libertates, gracias, privilegia et iura custodiat, et ea, que fuerint quadam oppressione, negligencia aut alias qualitercunque collapsa, reducat et ad redivive libertatis et justicie tramitem solidata confoveat, ut ipsi cives nostri et regni fideles Pragenses augmentis justicie et tranquilitatis efloreant atque in pacis amenitate feliciter conquiescant [...] - CIM I, S. 221.

47 Vgl. bereits die sinngemäße Privilegienbestätigungen für die Prager Altstadt durch König Johann den Blinden vom 11. Januar 1316 in CIM I, S. 21-22, Nr. 9, sowie König Karl IV. vom 27. Dezember 1348 ebd., S. 85-86, Nr. 51. 
seine Gnade getröstet fühlten. ${ }^{48}$ Im Fall der Prager Altstadt ist diese Behauptung nicht völlig unberechtigt, da die Prager sich bereits im Frühling 1434 jener Koalition des katholischen und des gemäßigten hussitischen Adels angeschlossen hatten, die danach die Feldheere bei Lipany besiegte. Die Altstadt spielte auch in den Verhandlungen mit dem Basler Konzil eine wichtige Rolle, in denen sie sehr kompromissbereit agierte, was Sigismund natürlich positiv ins Auge stechen musste. Die vorangehende Revolte der Prager Altstadt gegen den König wird in der Narratio selbstverständlich verschwiegen.

Das zweite Element der untersuchten Narrationes stellt der Verlust der städtischen Privilegien dar, die der Altstadt angeblich im vorangegangenen Krieg durch nicht näher spezifizierte Feinde geraubt worden waren. Logischerweise wird dieser Aspekt in C hervorgehoben, das eben die nicht mehr im Original vorhandenen, während des Hussitenkriegs vernichteten Privilegien der Altstadt bestätigte. ${ }^{49}$ Die Empfänger werden damit gewissermaßen ebenfalls als Opfer des vorangehenden Krieges präsentiert.

Das dritte Element bildet schließlich die Sonderstellung der Prager Altstadt, die in A durch die erwähnte spezielle Prager Arenga hervorgehoben, in B und C jedoch in der Narratio beschrieben wird. Besonders in B wird die Altstadt als Metropole und Haupt des Königreichs bezeichnet, aus dem Sigismund komme und alle seine Würden ableite. Die Prager Altstadt bilde den Thron seiner königlichen Hoheit und sei mit dem Licht der Gewohnheit, des Rechts und der Wissenschaften geschmückt, sodass sich die Früchte des Ruhms von ihrem grünen und fruchtbaren Garten aus in die anderen Städte und Regionen des Königreichs verbreiteten. ${ }^{50}$

Im Vergleich mit dem Urkundenkomplex für die Prager Altstadt ist die Privilegienbestätigung Sigismunds für die Prager Neustadt vom 1. Oktober 1436 wesentlich zurückhaltender formuliert. ${ }^{51}$ Diese im Original erhaltene Urkunde wurde zwar ebenfalls als feierliches Diplom mit Monogramm ausgestellt und mit Goldbulle besiegelt. Die Narratio erwähnt allerdings nur den Verlust der Neustädter Privilegien, die der Stadt während eines Aufstandes weggenommen worden seien. ${ }^{52}$ Sigismund würdigt keine Dienste der

48 Bereits geleistete Dienste führt eben nur A an: Nos autem considerantes multiplicibus meritis, quibus ipsi cives civitatis Maioris Pragensis nobis ac regno nostro Bohemie studiose complacuerunt et tanto placere poterunt fervencius in futurum, quanto largioribus graciarum muneribus se senserint a nostra clemencia uberius consolatos [...] - CIM I, S. 222. Dagegen werden die in der Zukunft zu erwartenden Dienste auch in C angesprochen, wo der Aussteller zu Beginn der Dispositio angibt, den Bitten der Empfänger Folge leisten zu wollen, ut ipsi in fide et devocione erga maiestatem nostram tanto firmius et sedulius perseverent, quanto se a nostra celsitudine senserint grandissimis beneficiis et graciis nedum consolatos [...] - CIM I, S. 225-226.

49 In der Petitionsformel von $\mathrm{C}$ heißt es: [...] qualiter alias in generali regni nostri Boemie orto disturbio, turbante omnium statutum et condicionum personas, ipsorum [PE: der Altstädter Bürger] certas litteras, privilegia et munimenta ipsis in grande dampnum et iacturam hostilis manus furibundo insultu ademit et subtraxit [...] - CIM I, S. 224.

50 Diese Metapher finden sich in der Petitionsformel von B: Sane pro parte magistri civium, juratorum, consulum necnon universorum civium peculiaris nostre Maioris civitatis Pragensis, que profecto dilectissimi et hereditarii nostri Bohemie regni, ubi et vite originem ac omnimode, qua fungimur, dignitatis fomenta nos suscepisse fatemur, metropolis et caput egregium et celsitudinis nostre regalis solium esse dinoscitur, morum, legum et scienciarum claritate ornatum, unde tamquam ab orto semper virescente ac irriguo in reliquas eiusdem regni civitates et partes fructuum honestatis grata derivatur ubertas, nostre serenitati exhibite sunt littere quam plures [...] - CIM I, S. 228.

51 CIM I, S. 230-232, Nr. 141.

52 In der Petitionsformel wird die Aussage der Neustädter Bürger zitiert: [...] qualiter novissime quadam 
Neustädter und betont lediglich, die Bürger würden ihm in Zukunft umso treuer sein, je mehr seine Barmherzigkeit sie mit Gnaden unterstützen würde. ${ }^{53}$

Die meisten Urkunden für utraquistische Empfänger gleichen eher dem Privileg für die Prager Neustadt, als jenem für die Altstadt: Meist werden keine durch den Empfänger geleisteten Dienste erwähnt, es wird jedoch der Hoffnung Ausdruck verliehen, dass solche folgen werden. Die vorangegangene Revolution und den Krieg werden nicht bewertet und nur dann erwähnt, wenn der Empfänger bedeutende Schäden erlitten oder Privilegien verloren hatte.

Dennoch gibt es einige Stücke, die aus bestimmten Gründen in der Narratio etwas detaillierter auf Ereignisse des Hussitenkriegs eingehen, weil es - aus verschiedenen Gründen - unvermeidlich war. Dies gilt zum Beispiel für Sigismunds bemerkenswerte Urkunde für Kuttenberg vom 19. März 1437. ${ }^{54}$ In der Narratio dieser Urkunde betont Sigismund, dazu verpflichtet zu sein einen Beitrag zu leisten, um die Stadt Kuttenberg, den größten und nützlichsten Schatz und das Kleinod des Königreichs, wieder aufzurichten und die dortigen Bergwerke nach der langjährigen und für das ganze Land sehr schädlichen Vernachlässigung wieder in Betrieb zu setzen. Nach vielen Beratungen und Befragungen habe er erkannt, dass die einzige Lösung in der Rückkehr der alten Bergleute liege, die die Bergwerke gut kannten und sie gemeinsam mit den jetzt in Kuttenberg lebenden Bergleuten wieder instand setzen könnten. Er habe die alten sowie die neuen Bergleute vor sich geladen, und diese ersucht, einen Kompromiss zu finden, da es sich andernfalls für ihn nicht lohne, Kuttenberg zu unterstützen und wiederaufzurichten. Daraufhin hätten sich die alten und die gegenwärtigen Kuttenberger versammelt und am 6. Februar vor ihm und dem allgemeinen böhmischen Landtag in Prag öffentlich bekannt gegeben, dass sie sich nach den vergangenen Fehden und Streitigkeiten christlich versöhnt hätten und zu einer Übereinkunft gekommen seien. Der Rest der Narratio vermittelt den Inhalt des detaillierten Übereinkommens, das Sigismund dann in der Dispositio gemeinsam mit den alten städtischen Freiheiten und Privilegien bestätigte und um einige neue Gnaden und Rechte erweiterte.

Die Aussöhnung der sog. „alten“, i. e. der vornehmlich deutschsprachigen und katholischen Bergleute, die im Frühling 1421 erstmalig, und Anfang 1422 endgültig aus der Stadt vertrieben worden waren, mit den „neuen“, vorwiegend tschechischen und utraquistischen Bergleuten stellt einen eher unüblichen Abschluss der religiösen, sozialen

sedicione in eorum civitate suborta litteris originalibus privilegiorum, iurium, libertatum, graciarum et emunitatum necnon ratificacionum, approbacionum et confirmacionum earundem sunt orbati [...] - CIM I, S. 230. Weiter unten in der Narratio fügt der Aussteller - nach einer eingeschobenen Arenga - hinzu: Ast eciam sinistre sortis occursus in huius regni nostri hereditarii generali disturbio omnis status et condicionis involvente passim et turbante personas damnose oppressit et munimenta litterarum et privilegiorum hincinde in puribusque locis hostili manu ademit $[. .$.$] - ebd., S. 231$.

$53[. .$.$] itaque prefatorum civium racionalibus et iustis supplicacionibus favorabiliter annuentes, ut in fide et devocione$ erga maiestatem nostram tanto firmius et solidius perseverent, quanto se a nostra celsitudine senserint huiusmodi grandissimis beneficiis et graciis nedum consolatos, sed de novo donatos [...] - ebd.

54 CIM III, S. 194-200, Nr. 114. Siehe dazu Kejř, Jiří: Právní život v husitské Kutné Hoře I [Das Rechtsleben im hussitischen Kuttenberg]. Kutná Hora 2002, S. 68, 109-110; Štroblová, Helena - Altová, Blanka u. a.: Kutná Hora [Kuttenberg]. Praha 2000, S. 67-68. 
und nationalen Konflikte in den böhmischen Städten während der Hussitenzeit dar. Um diese Versöhnung in den entsprechenden Kontext zu setzten, musste der vorangehende Konflikt in der Narratio von Sigismunds Urkunde kurz angesprochen werden. Dies geschah jedoch wiederum indirekt und sehr vorsichtig; die nicht zu leugnende Vertreibung der alten Bergleute wird nicht einmal mit dem Hussitismus in Verbindung gebracht. In den Vordergrund werden vor allem die Kriegsereignisse gestellt, die die Stadt und den Bergbau ruiniert hätten.

Die jüngere Vergangenheit musste auch in etlichen Pfandbriefen thematisiert werden, mit welchen Sigismund utraquistischen Empfängern durch dieselben faktisch beherrschte kirchliche oder Kammergüter verpfändete. In der Narratio musste jeweils erklärt werden, wie das betreffende Gut in die Hände des Empfängers gekommen war. Ein besonders aufschlussreiches Beispiel einer solchen Urkunde stammt aus Nordostmähren: es handelt sich um einen Pfandbrief für Nikolaus Sokol von Lamberg vom 25. Februar 1437 über die Doppelburg Hochwald, die Stadt Ostrau, das Gut Schauenstein und weitere Güter des Bistums Olmütz in der Gegend. ${ }^{55}$ Sigismund beschreibt in der Narratio die Geschichte der verpfändeten Güter, besonders Hochwalds, während der letzten Jahrzehnte. Vor einiger Zeit habe er mit Zustimmung des Bischofs und des Domkapitels von Olmütz die beiden Burgen von Hochwald mit allem Zubehör Herzog Bolko von Oppeln verpfändet. ${ }^{56}$ Bolko habe jedoch vor einiger Zeit diese Burgen an „gewisse, solche Leute“ verloren (kteréžto hrady pod chvilemi ztratil jest těm a takovým lidem), woraufhin diese Leute von Hochwald aus dem Land Mähren große Schäden zugefügt hätten. Dann seien die Burgen durch den Edlen Johann von Zinnburg zu Tobitschau an den Edlen Nikolaus Sokol von Lamberg verkauft worden. Sigismund habe sich in der Folge mit Nikolaus nicht anders einigen können, als ihm die Burgen mit allen Dörfern und allem Zubehör, sowie das Gut Schauenstein, das Nikolaus gehörte, ${ }^{57}$ mit allem Zubehör um 3.000 Schock Prager Groschen abzukaufen. In der Dispositio folgt dann die Verpfändung der fiktiv gekauften Güter an Nikolaus Sokol um genau diese 3.000 Schock.

Der fiktive Kauf und die sofortige Verpfändung der Burgen an den ehemaligen taboritischen Hauptmann Nikolaus Sokol stimmt mit der These Stanislav Bártas von der Verwendung von Pfandbriefen als Instrument zur politischen Stabilisierung Böhmens

55 Siehe die Edition bei Jurok, Jiří: Moravský severovýchod v epoše husitské revoluce [Nordost-Mähren in der Zeit der hussitischen Revolution]. Nový Jičín 1998, S. 207-208, Nr. 8; eine Analyse des Stücks ebd., S. 79-80, 102-103, 121 und 167-168; siehe auch Bakala, Jaroslav u. a.: Dějiny Ostravy [Geschichte der Stadt Ostrau]. Ostrava 1993, S. 46-48; jüngst Elbel, Petr: „Scio quod vos Moravi estis timidi et michi non fideles“. Moravané ve strukturách dvora Zikmunda Lucemburského [,Scio, quod vos Moravi estis timidi et michi non fideles“. Personen aus Mähren in den Hofstrukturen Sigismunds von Luxemburg]. Mediaevalia Historica Bohemica 12/2, 2009, S. 43-132, hier S. 120-121.

56 Es wird verschwiegen, dass Sigismund diese Güter zuvor vom Olmützer Bischof Johann Mráz in Schutz und Pfand übernommen hat. Siehe dazu die Urkunden Sigismunds vom 1. und 4. Januar 1400 - Codex diplomaticus et epistolaris Moraviae. XIII. Vom Jahre 1400 bis 1407. Hg. von Vincenz Brandl. Brünn 1897, S. 1, Nr. 1; S. 2, Nr. 2.

57 Es handelte sich ebenfalls ursprünglich um ein Gut des Bistums Olmütz, das bereits vor dem Hussitenkrieg an die Herren von Lamberg gekommen war. Der Autor plant, die Geschichte der Burg Schauenstein in der Hussitenzeit aufgrund einer bisher unberücksichtigten Quelle in einem Aufsatz zu bearbeiten. 
in den Jahren 1436/37 völlig überein. ${ }^{58}$ Hier beschäftigt uns jedoch wiederum die Frage, was in der Narratio der Urkunde behauptet bzw. verschwiegen wurde. Die gezielte Verschweigung des Hussitismus und der Revolution sticht hier besonders ins Auge. Jene Hussiten, die Herzog Bolko von Oppeln die Burg Hochwald abnahmen, werden neutral als „gewisse, solche Leute“ bezeichnet, die von dort aus viele Schäden verursachten. Der Verkauf der Burg durch einen der aktivsten hussitischen Herren in Mähren, Johann von Zinnburg, an den taboritischen Hauptmann Nikolaus Sokol wird ebenfalls so präsentiert, als ob es sich um ein gewöhnliches Geschäft unter zwei Adeligen und nicht um einen strategischen Transfer innerhalb des hussitischen Lagers gehandelt hätte. Darüber hinaus verschweigt die Urkunde auch die Tatsache, dass Sigismund bereits im Jahr 1435, während der Verhandlungen mit den Hussiten in Brünn, einen Versuch unternahm, die Burg Hochwald von Nikolaus Sokol auszulösen; ein Versuch, der letztlich trotz der darüber ausgestellten Urkunde wirkungslos blieb. ${ }^{59}$

Insgesamt stellt die Narratio der Urkunde vom 25. Februar 1437 ein sehr instruktives Beispiel dafür dar, wie differenziert und selektiv die Kanzlei Sigismunds die Erinnerung an den Hussitenkrieg aufbereitete.

$$
* * *
$$

An diese Feststellung kann wohl die Conclusio anknüpfen. Der Beitrag zeigte, dass die Erinnerung an den Hussitenkrieg in den Narrationes der Urkunden Kaiser Sigismunds während der fünf Jahre von 1433 bis 1437 einen bemerkenswerten Wandel erlebte. Während zu Beginn des Untersuchungszeitraums die Urkunden für königstreue katholische Empfänger in den Narrationes deren treuen, standhaften und aufwendigen Kampf gegen die „hussitische Häresie“ thematisierten, änderte sich dies nach Abschluss der Kompaktaten in Iglau vollkommen. Die kaiserlichen Urkunden für Katholiken lobten nun nur noch die ständige Treue der Empfänger im vorangegangen Krieg und hoben die dabei erlittenen Schäden hervor, ohne den Krieg oder den Feind irgendwie zu bezeichnen bzw. zu bewerten.

Am markantesten ist dieser Wandel jedoch in den Narrationes der Urkunden für utraquistische Empfänger zu beobachten, welche in den Jahren 1436/37 massenhaft produziert wurden. Hier konnten nur selten treue Dienste der Empfänger hervorgehoben werden, weshalb einerseits Dienste ihrer Vorfahren, andererseits von ihnen zu erwartende Dienste erwähnt werden. Daneben wurden natürlich auch hier Schäden angesprochen, die der/die Empfänger im vorangehenden Krieg erlitten hatten, und die zum Teil durch das Fehlen eines legitimen Herrschers erklärt wurden, der den/die Empfänger beschützen hätte können. Utraquistische Empfänger, vor allem unter den Städten, wurden damit also teilweise zu Opfern der (hussitischen) Revolution und des (Hussiten-)Krieges erklärt. Der vorangegangene Krieg, der Aufstand oder die Verwir-

58 Siehe Bárta, S.: Zástavní listiny, S. 84-90.

59 Am 9. August 1435 stellte Kaiser Sigismund in Brünn eine Urkunde aus, durch die er sich verpflichtete, Nikolaus Sokol von Lamberg 600 Schock Prager Groschen in bar oder in Pferden und Ochsen zu bezahlen, da Nikolaus auf seinen Wunsch dem Bischof von Olmütz die Burg Hochwald zurückerstattet hatte - siehe HHStA Wien, RR K, fol. 235v (alt: 224v); Kurzregest in RI XI-2, S. 356, Nr. 11166. Angesichts der Urkunde vom 25. Februar 1437 ist es offensichtlich, dass dieses Geschäft nicht zustande kam. 
rung im Königreich Böhmen wurden hier jedoch nie mit einem Epitheton versehen, sondern stets nur allgemein als solche bezeichnet. Dies gilt auch für solche Urkunden, die nicht umhin kamen, in der Narratio bestimmte Ereignisse der letzten beiden Jahrzehnte näher zu thematisieren (die Vertreibung der [katholischen, deutschsprachigen] Bergleute aus Kuttenberg [durch die Hussiten]; die Eroberung einer an Herzog Bolko von Oppeln verpfändeten Burg der Bischöfe von Olmütz [durch die Hussiten] usw.). Die Narrationes der Urkunden Kaiser Sigismunds aus den Jahren 1436/37 belegen jedenfalls die konsequente Beachtung der Kompaktaten durch die (Reichs-)Hofkanzlei.

\section{Narace listin císaře Zikmunda pro české př́ijemce z let 1433-1437 a proměny paměti husitských válek}

Přestože listiny v pozdním středověku byly již dávno konstitutivními právními dokumenty, stále hrály nemalou roli též pro fixaci kolektivní paměti. Nešlo přitom jen o pamět na různé rituální akty, doprovázející daný právní počin, ale i o jeho celkový kontext. V tomto ohledu měly klíčovou roli především narace, které nás uvádějí do právního i historického kontextu listiny.

Studie se zaměřuje na narace listin Zikmunda Lucemburského pro české př́ijemce z let 14331437. V tomto dramatickém období na jednu stranu vrcholily husitské války (obležení Plzně, bitva u Lipan), současně s tím však již probíhala jednání mezi husity a basilejským koncilem, která vyústila ve vyhlášení kompaktát a přijetí císaře Zikmunda za českého krále v červenci 1436 . Ve třech oddílech autor postupně analyzuje narace Zikmundových listin pro české katolíky v letech 1433-1435 a v letech 1436-1437, resp. narace listin pro utrakvisty z období 1436-1437 (předtím Zikmund téměř žádné listiny pro utrakvisty nevydával).

V letech 1433-1435 listiny písemně fixovaly pamět katolických měst a šlechtických rodů na jejich vytrvalý a udatný boj proti „husitské herezi“, přičemž Zikmundova kancelář používala obvyklé stereotypní výrazy pro popis nepř́tele a jeho zločinů. V letech 1436-1437 však kancelář obratně modifikovala pamět předešlých válečných událostí tak, aby výsledný obraz odpovídal náboženskému smíru z července 1436 . V listinách pro katolíky byla vyzdvihována jejich věrnost panovníkovi v minulých válkách a nepokojích, které však nejsou nijak blíže specifikovány. Katolická města si proto někdy nechala pamět na svo̊j dlouholetý boj proti „heretikům“ potvrdit jinou autoritou, jak ukazuje pozoruhodná listina olomoucké biskupské kapituly pro město Olomouc z jara 1436, anebo si příslušnou pamět sama zapsala do své městské knihy, jak ukazují historiografické texty olomouckého městského písaře Václava z Jihlavy v jím založené městské knize.

V Zikmundových listinách pro utrakvisty bylo období válek bud' zcela vypuštěno (pak se zdůrazňují věrné služby př́ijemců či jejich předků Zikmundovým předchůdcům a jejich ochota v budoucnu také Zikmundovi věrně sloužit), anebo se i zde neutrálně zmiňovaly předešlé nepokoje v Českém království, v nichž př́ijemci utrpěli četné škody. Utrakvističtí př́ijemci, zejména města, pak byla vlastně prezentována také jako oběti husitské revoluce a husitských válek. Důmyslná práce kanceláře s pamětí nedávno minulých událostí je na závěr podrobněji ilustrována několika signifikantními příklady z utrakvistického prostředí (privilegia pro Staré Město pražské, Kutnou Horu, zástavní listina pro Mikuláše Sokola z Lamberka). 
